JGG 2020;68:123-125

doi: 10.36150/2499-6564-393

\title{
Prevalence of frailty in surgical older patients and its impact on assisted discharge
}

\author{
Silvia Ronchi', Matteo Cesari², Emanuela Racaniello ${ }^{1}$, Elena De Rosa ${ }^{1}$, \\ Roberto Accardi ${ }^{1}$ \\ ${ }^{1}$ Healthcare Professionals Department, Foundation IRCCS Ca' Granda Ospedale Maggiore \\ Policlinico, Milan, Italy; ${ }^{2}$ Geriatric Unit, Foundation IRCCS Ca' Granda Ospedale Maggiore \\ Policlinico, Department of Clinical Sciences and Community Health, University of Milan, Italy
}

Background \& aim. An increasing number of older persons is today undergoing emergency and elective surgical procedures. Frailty is a highly prevalent condition and a predictor of postoperative adverse outcomes. This study is aimed at measuring the prevalence of frailty among older persons awaiting for surgical procedures, and the activation of services supporting protected discharge from the hospital in individuals with high vulnerability to stressors.

Methods. A prospective observational study was conducted in patients aged 65 years and older waiting for surgery. Frailty was measured using the criteria proposed by Robinson and colleagues. Length of stay and care services activated at the discharge recorded.

Results. A total of 1,144 patients were recruited. Two-hundred and seventeen (19\%) patients were defined as frail, and $395(34.5 \%)$ were pre-frail. The average length of post-operative stay was 5 days. Only $39(3.4 \%)$ patients received care plan assuring a protected discharge. Among these, $35(89.7 \%)$ were frail, $4(10.3 \%)$ pre-frail. The variable most strongly correlated with the activation of services supporting an assisted discharge was the dependence in activities of daily living $(\rho=0.27, p<0.001)$.

Conclusions. Frailty is a highly prevalent condition among persons undergoing emergency and elected surgery procedures. Nevertheless, services supporting assisted discharge on the territory are quite infrequently activated. An improved integration of care services bridging hospital and community is necessary and therefore a lack of continuity of health and social care. Further research should focus on the postoperative management of the frail elderly patient.

Key words: surgery, frailty, discharge, elderly

\section{INTRODUCTION}

Frailty is defined as a medical condition with multiple causes and contributors that is characterised by reduced physiological reserves, increasing the aging individual's vulnerability and exposing him/her to the risk of negative health outcomes (including dependency and/or death) ${ }^{1,2}$. Several studies associate the frailty with unfavourable endpoints in surgical patients, including increased post-surgical mortality, higher number of complications, longer hospital stay, and risk of post-discharge re-admission ${ }^{2-7}$. It is thus \author{
sari M, Racaniello E, et al. Prevalence of \\ frailty in surgical older patients and its im- \\ pact on assisted discharge. Journal of Ge- \\ rontology and Geriatrics 2020;68:123-5. \\ https://doi.org/10.36150/2499-6564-393 \\ (C) Copyright by Società Italiana di Gerontologia e \\ Geriatria (SIGG) \\ This is an open access article distributed in accor- \\ dance with the CC-BY-NC-ND (Creative Commons \\ Attribution-NonCommercial-NoDerivatives 4.0 Inter- \\ national) license. The article can be used by giving \\ appropriate credit and mentioning the license, but \\ only for non-commercial purposes and only in the \\ original version. For further information: https://creati- \\ vecommons.org/licenses/by-nc-nd/4.0/deed.en \\ (c) (1) $(9)$ \\ Roberto Accardi \\ Healthcare Professionals Department \\ 20121 Milan, \\ Funding \\ Conflict of interest \\ The Authors declare no conflict of interest
}


not surprising the reported association between frailty and increased healthcare expenditures ${ }^{8}$.

The present study is aimed at: 1) measuring the prevalence of frailty in patients undergoing emergence or elective surgery, and 2) documenting how many times care services designed for protected hospital discharge are activated.

\section{MATERIALS AND METHODS}

Data are from a prospective study performed in a university hospital of Milan (Italy) between October 2016 and December 2017. The research was in accordance with the principles of Declaration of Helsinki. Inclusion criteria were: age equal to or older than 65 years; admission to one of the hospital surgical units (i.e., Thoracic Surgery, Hepato-bilio-pancreatic Surgery, Vascular Surgery, and General and Emergency Surgery).

Frailty was defined according to the criteria proposed by Robison et al. ${ }^{6,9}$, as specifically developed for surgical patients. This simple tool was created as a screening tool for frailty in order to recognize the unique physiologic vulnerabilities of the geriatric population and evaluate the risk of poor postoperative outcome. In particular, the following criteria were measured at baseline before the surgical intervention:

1. Dependence in the activities of daily living (ADL; i.e., presence of 1 or more impaired ADL at the Katz' scale);

2. Poor result (15 seconds or more) at the Timed Upand-Go test;

3. High comorbidity burden (i.e., Charlson Comorbidity Index > 3);

4. Poor cognitive function (i.e., Mini-Cog test $\leq 3$ );

5. Malnutrition $\left(\mathrm{BMl}<18.5 \mathrm{~kg} / \mathrm{m}^{2}\right.$ or $\left.\mathrm{BMl}>25 \mathrm{~kg} / \mathrm{m}^{2}\right)$;

6. History of one or more fall events in the past 6 months;

7. Anaemia (i.e., haematocrit < 35\%).

Patients were grouped into three groups according to the number of presented criteria:

- non-frail: 0 or 1 criterion is present;

- pre-frail: 2 o 3 criteria are present;

- frail: $\geq 4$ criteria are present.

\section{Statistical ANALYSIS}

Descriptive statistics were applied to show the main characteristics of the study sample. Spearman's correlation analyses were performed. Statistical analysis was conducted using Stata 11.2 for Windows ${ }^{\circledR}$.

\section{RESULTS}

The study population included 1,144 subjects, predominantly men (56\%), admitted for elective surgery (80\%). Mean age was 75 (standard deviation, SD 6.7) years (range 65-96 years). The type of surgery at the basis of the hospitalization was hepatic/pancreatic surgery, vascular surgery, thoracic surgery, emergency surgery, and general surgery in 124, 209, 240, 259, and 312 cases, respectively. The average length of postoperative stay was 5 (SD 7.0) days.

Prevalence of frailty syndrome was 19\% ( $n=217)$, whereas $34 \%$ of subjects $(n=395)$ were pre-frail. The most prevalent frailty criteria were poor physical performance (54\%), comorbidity (29\%), cognitive impairment (32\%) and ADL disability (28\%). Frailty was positively correlated with age, emergency surgery, major intervention, and longer postoperative stay.

Post-discharge care services were activated at the end of the hospital stay only for 39 patients, all frail $(n=35)$ or pre-frail $(n=4)$. The correlation between frailty and protected hospital discharge was statistically significant ( $\rho=0.28, p<0.001)$, and strongly related to ADL disabilities $(\rho=0.27, p<0.001)$. The presence of social support represented by an informal caregiver does not seems to influence the activation of post-discharge care services.

\section{DISCUSSION}

Our study shows that the prevalence of frailty in the older person undergoing emergence or elective surgery is relatively high $(19,53.5 \%$ if considering both frail and pre-frail individuals).

Current methods for preoperative risk stratification in the elderly, focused on a single organ system or solitary event or established from clinical trials that excluded the geriatric population, cannot measure the older patient's physiological reserves appropriately ${ }^{10}$. Comprehensive Geriatric Assessment represent the key point of preoperative assessment to of surgical geriatric patient andensures that problems are identified, quantified, and managed appropriately by involving a multidisciplinary team. Medical, psychiatric, functional, and social assessments are required to develop a multidimensional therapeutic approach to enhance recovery and prevent disability ${ }^{11}$. A recent Italian multicenter observational study, by Abete et al. show that comprehensive geriatric assessment can predict a higher risk of adverse outcomes (mortality and morbidity) independent of established surgical risk assessment tools ${ }^{11}$. Similarly, our results show that the evaluation of frailty syndrome, carried out by the evaluation of Robinson's criteria, allows the identification of subjects at risk of adverse postoperative discharge. Nevertheless, despite frailty should be managed by promoting integration of care and developing personalized 
plan of interventions bridging hospital services with the community, a very low number of patients benefited of protected discharge. Continuity of health care is crucial for improving and optimizing outcomes in surgical patients. In particular, multidisciplinary and comprehensive plans of care supporting the frail patient after surgery in his/her coming back at home are crucial for avoiding negative health outcomes for the individual and the waste of healthcare resources (e.g., functional decline of the patient, re-hospitalizations, Emergency Room admissions, surgical complications ect.). The presence of frailty should indeed direct the clinicians' decisions towards the activation of an adapted care plan based on the integration of care services. Otherwise, it might also be argued the value and clinical relevance of frailty itself.

As expected, the prevalence of frailty we reported is higher than what usually found in community-dwelling older persons ${ }^{12}$. Our result is similar to what previously reported by McCarthy et al. (i.e., 19.2\%) in a research conducted in a population similar to ours ${ }^{13}$.

Our study has several limitations to be noted. The study was conducted in one single university hospital. Our results may thus reflect activities ongoing at this site, and not necessarily be representative of other settings and clinical sites. The assessment of frailty was conducted before the surgical intervention. It is possible that the frailty status might have changed after the surgical intervention. Data show that Robinson's tool is easy to use in clinical contexts and is not time-consuming: it is therefore a useful screening tool. On the contrary, this tool do not take into consideration the analysis of the patient's emotional/psychological state. The multidimensional geriatric evaluation is more complete but requires the intervention of experienced and qualified staff such as the geriatrician and longer times for the assessment and it could be difficult to use in emergency surgery context.

In conclusion, our findings show that integration of care for frail older persons is still lacking, even in settings (as the post-surgical one) where frailty is highly prevalent. Frailty should be routinely measured as part of the preoperative patient's risk assessment. Nevertheless, in order to avoid that such assessment remains a sterile collection of data, it is necessary that results are transformed in proactive strategies aimed at personalizing interventions and care decisions.

\section{References}

1 Hewitt J, Moug SJ, Middleton M, et al. Prevalence of frailty and its association with mortality in general surgery. The
Am J Surg 2015;209:254-9. https://doi.org/10.1016/j. amjsurg.2014.05.022

2 Ronchi S, Accardi R, Lusignani M. Elderly and surgery: impact of frailty on surgical outcome. A literature review. Professioni Infermieristiche, 2019 settembre;72. (http:// www.profinf.net/pro3/index.php/IN/article/view/626).

3 Revenig LM, Canter DJ, Kim S, et al. Report of a simplified frailty score predictive of short-term postoperative morbidity and mortality. J Am Coll Surg 2015;220:904-11.e1. https://doi.org/10.1016/j.jamcollsurg.2015.01.053

4 Ambler GK, Brooks DE, Al Zuhir N, et al. Effect of frailty on short- and mid-term outcomes in vascular surgical patients. Br J Surg 2015;102:638-45. https://doi. org/10.1002/bjs.9785

5 Amrock LG, Neuman MD, Lin H-M, et al. Can routine preoperative data predict adverse outcomes in the elderly? Development and validation of a simple risk model incorporating a chart-derived frailty score. J Am Coll Surg 2014;219:684-94. https://doi.org/10.1016/j.jamcollsurg.2014.04.018

6 Robinson TN, Wu DS, Pointer L, et al. Simple frailty score predicts postoperative complications across surgical specialties. Am J Surg 2013;206:544-50. https://doi.org/ 10.1016/j.amjsurg.2013.03.012

7 Dale W, Hemmerich J, Kamm A, et al. Geriatric assessment improves prediction of surgical outcomes in older adults undergoing pancreaticoduodenectomy: a prospective cohort study. Ann Surg 2014;259:960-5. https://doi. org/10.1097/SLA.0000000000000226

8 Joseph B, Pandit V, Sadoun M, et al. Frailty in surgery. J Trauma Acute Care Surg 2014;76:1151-6. https://doi. org/10.1097/TA.0000000000000103

9 Robinson TN, Wallace JI, Wu DS, et al. Accumulated frailty characteristics predict postoperative discharge institutionalization in the geriatric patient. J Am Coll Surg 2011;213:37-42; discussion 42-4. https://doi. org/10.1016/j.jamcollsurg.2011.01.056

$10 \mathrm{Kim} \mathrm{S}$, Han H-S, Jung $\mathrm{H}$, et al. Multidimensional frailty score for the prediction of postoperative mortality risk. JAMA Surgery 2014;149:633. https://doi.org/ 10.1001/ jamasurg.2014.241

11 Abete P, Cherubini A, Di Bari M, et al. Does comprehensive geriatric assessment improve the estimate of surgical risk in elderly patients? An Italian multicenter observational study. Am J Surg 2016;211:76-83.e2.

12 Bavazzano A, Ed. Linee Guida Regione Toscana - La fragilità nell'anziano. 2013 (http://www.regione.toscana.it/ consiglio-sanitario-regionale/linee-guida).

${ }_{13}$ McCarthy K, Moug S, Stechman M, et al.; on behalf of the Older Persons Surgical Outcomes Collaboration (OPSOC). 52 * The prevalence of frailty in the acute general surgical setting. Age Ageing 2014;43(Suppl 2):ii16. 